\title{
Desain dan Implementasi Mekanisme Smart Forklift pada AGV Berbasis Raspberry Pi 4 Model B
}

\author{
Phoa Marcellino Siva ${ }^{\mathrm{a} 1}$, Florentinus Budi Setiawan ${ }^{\mathrm{a} 2}$, Slamet Riyadi ${ }^{\mathrm{a} 3}$, Leonardus Heru Pratomo ${ }^{\mathrm{a} 4}$ \\ ${ }^{a}$ Program Studi Teknik Elektro, Universitas Katolik Soegijapranata \\ Jl. Pawiyatan Luhur Sel. IV, Gajahmungkur, Semarang \\ ${ }^{1}$ phoamarcellino@gmail.com \\ 2fbudis@yahoo.com \\ ${ }^{3}$ tu.elektro@unika.ac.id
}

\begin{abstract}
Abstrak
Automatic Guided Vehicle (AGV) pallet truck merupakan salah satu jenis AGV yang banyak digunakan di industri. AGV jenis ini merupakan kombinasi AGV dengan mekanisme forklift. Mekanisme forklift digunakan untuk mengangkat dan membawa barang dari satu titik ke titik yang lainnya. Seiring dengan berkembangnya teknologi yang disertai dengan revolusi industri 4.0 maka kegiatan tersebut dapat dilakukan secara otomatis dengan menggunakan robot seperti AGV pallet truck. Pada dasarnya, mekanisme kerja dari AGV pallet truck sama seperti forklift pada umumnya, hanya saja AGV pallet truck sudah beroperasi secara otomatis. Motor DC (Direct Current) banyak digunakan sebagai motor penggerak untuk proses naik turun dalam mekanisme forklift pada AGV pallet truck. Motor DC dipilih karena memiliki torka yang besar untuk pengangkatan beban. Namun, motor DC juga memiliki beberapa kelemahan seperti biaya perawatannya yang mahal dan tingkat kepresisiannya masih kurang akurat. Pada penelitian ini diusulkan mekanisme smart forklift untuk AGV pallet truck yang menggunakan motor stepper dengan tingkat kepresisian tinggi dan torka yang dimiliki juga tidak kalah dengan motor DC. Mekanisme smart forklift diperlengkapi sensor jarak untuk mengukur ketinggian forklift dan jarak antara AGV dengan palet serta raspberry pi 4 model B sebagai controller.
\end{abstract}

Kata kunci: AGV, forklift, mekanisme, raspberry pi

\section{Desaign and Implementation Smart forklift Mechanism on AGV Based on Raspberry Pi 4 B Model}

\begin{abstract}
Automatic Guided Vehicle (AGV) pallet truck is widely used in industry. This kind of AGV is such a combination of the ordinary AGV used with forklift mechanism. The forklift mechanism is employed for lifting or carrying things from one place to another place. As the technology have been developed along with the industry revolution 4.0 therefore the activity could be done automatically by using a robot like AGV pallet truck. Basically, the work principle of AGV pallet truck is similar with the ordinary forklift whereas the AGV pallet truck is automatically operated. DC motor (Direct Current) is applied as the driving force for up lifting and down lifting process in forklift mechanism of AGV pallet truck. DC motor is chosen since it has large torque which is advantageous for lifting loads. Unfortunately, DC motor also owns some disadvantages such as high maintenance fee and less precision. This study proposes a smart forklift mechanism for AGV pallet truck that utilizes a stepper motor with an excellent precision and has large torque similar with DC motor. This smart forklift mechanism is equipped with a proximity sensor for measuring the height of forklift and the distance between AGV and the pallet also using raspberry pi 4 as the controller.
\end{abstract}

Keywords: AGV; forklift; mechanism; raspberry pi

\section{Pendahuluan}

Revolusi industri 4.0 semakin berkembang dengan pesat. Efektivitas dan efisiensi yang tinggi inilah yang ditawarkan revolusi industri 4.0 [1]. Di Indonesia, revolusi industri 4.0 juga sudah merambat ke berbagai sektor, terutama dibidang industri. Dengan adanya revolusi industri 4.0 yang dimana semua serba otomatis, digitalisasi, dan cepat maka pemenuhan logistik di lingkungan industri pun juga tidak luput dari revolusi ini. AGV yang merupakan singkatan dari Automated Guided Vehicle merupakan salah satu terobosan untuk membantu bagian logistik dalam beroperasi [2]. AGV sejak pertama kali diciptakan banyak digunakan untuk keperluan pengantaran barang dari satu bagian ke bagian lainnya dengan cepat dan terarah[2]-[4]. Sehingga dengan begitu 
para operator maupun pekerja tidak perlu bolak balik hanya untuk mengantar suatu berkas ataupun barang. AGV terbagi menjadi beberpa kategori salah satunya adalah jenis pallet truck [2]. AGV kategori tersebut telah mengadopsi sistem forklift pada umumnya dalam membwa dan memindahkan barang.

Mekanisme AGV pallet truck yang banyak dikembangkan rata - rata banyak menggunakan motor dc yang digunakan sebagai penggerak utamanya dalam proses pengangkatan atau pun penurunan [5], [6]. Menggunakan motor dc sebab motor dc memiliki torka yang besar sehingga mampu mengangkat beban yang berat [7], [8]. Namun, motor dc memiliki beberapa kelemahan seperti perawatannya yang dimana pada motor dc terdapat sikat dan komutator yang saling bergesekan dan menghasilkan endapan karbon didalam motor dc. Selain itu jika ingin bergerak untuk lebih presisi butuh pengolahan yang ekstra untuk mengendalikan motor dc. Motor stepper merupakan sebuah terobosan dalam motor elektrik karena memiliki torka yang besar dan tingkat kepresisianyang tinggi [9], [10].

Pada penelitian ini diusulkan mekanisme smart forklift untuk AGV pallet truck yang berbasis raspberry pi 4 model B. Raspberry pi mampu digunakan sebagai sebuah mikrokontroller juga sebab memiliki GPIO yang berjumlah 40 pin lebih banyak daripada arduino Mega 2560. Raspberry pi juga memiliki clock speed dan RAMyang lebih besar dari Arduino Mega juga memiliki fitur yang lebih lengkap [11].

\section{Metodologi}

Alur penelitian yang dilakukan ditunjukkan pada diagram alir berikut pada gambar 1 .

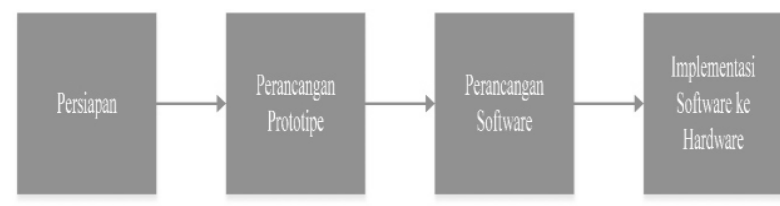

Gambar 1 Diagram Alir Alur Penelitian

Berdasarkan diagram alir tersebut penelitian ini dibagi menjadi 4 tahap yakni:

1) Persiapan : Pada tahap persiapan yang dilakukan antara lain melakukan tinjauan pustaka seputar AGV, forklift, dan raspberry pi. Setelah itu mulai menentukan skema kerja prototipe yang akan dibuat dan menentukan bahan-bahan yag dibutuhkan.

2) Perencanaan Prototipe : Setelah melakukan peninjauan pustaka atau sumber referensi yang terkait dengan penelitian maka dilakukanlah tahap perancangan hardware mengenai bagaimana skema kerja prototipe yang akan dibuat. Pada prototipe kali ini komponen utama yang digunakan antara lain :

a. Motor stepper sebagai penggerak mekanisme forklift.

b. Lead screw sebagai poros putar.

c. Motor dc sebagai roda penggerak d. Sensor ultrasonik yang berfungsi sebagai sensor jarak untuk mendeteksi ketinggian dan jarak antara AGV dengan palet

Wujud dari prototipe yang telah dirancang dan sistem mekanisme tersebut dapat dilihat pada gambar 2 .

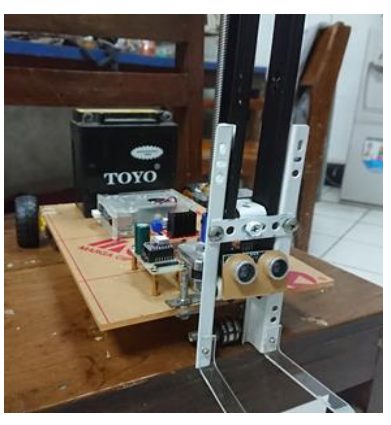

(a)

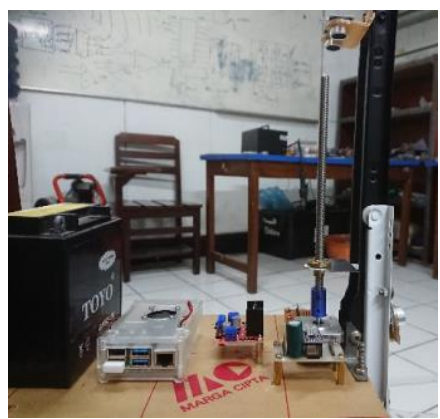

(b)
Gambar 2 Prototipe mekanisme forklift a) tampak depan, b) tampak samping

3) Perancangan Software: Pada tahap ini dilakukan pemetaan lebih lengkap mengenai bagaimana proses urutan kerja dari mekanisme forklift. Alur software yang dirancang disesuaikan dengan kebutuhan dan juga disesuaikan dengan alur kerja dari AGV yang dibuat. Diagram alir dari perancangan software yang ada dapat dilihat pada gambar 3 .

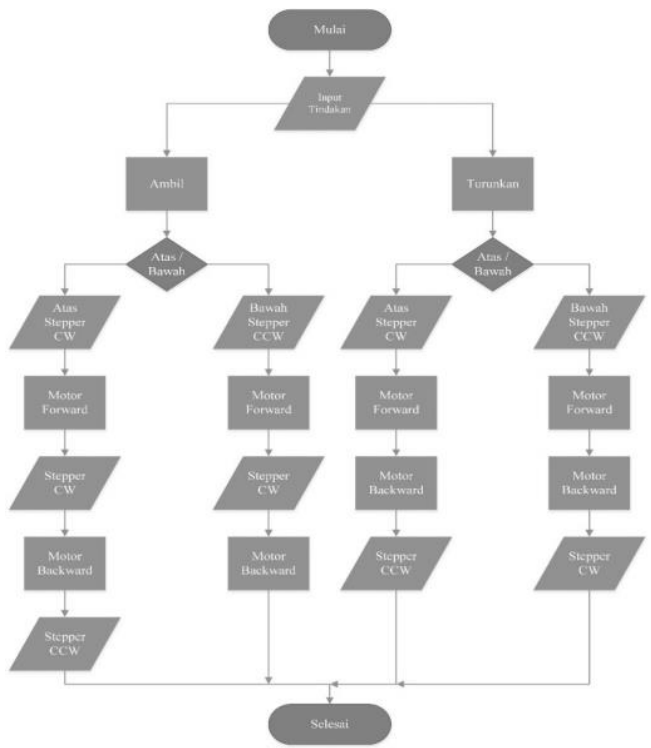

Gambar 3 Diagram Alir Software Mekanisme Forklift

4) Implementasi Software ke Hardware: Tahap implementasi merupakan tahap penggabungan antara software dengan hardware. Secara lengkap hubungan dari semua komponen utama penyusun mekanisme forklift dengan rangkaian kontrolnya ditunjukkan pada gambar 7 . 


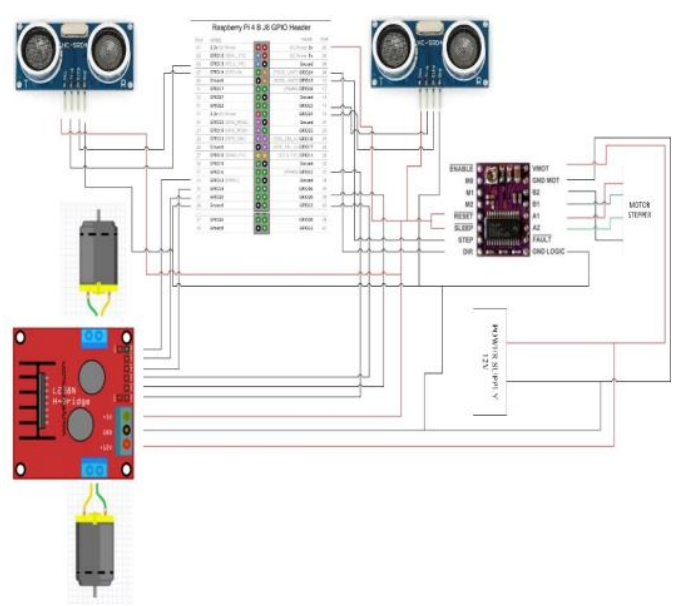

Gambar 4 Skema Rangkaian Kontrol

\section{HASIL DAN PEMBAHASAN}

Pengujian dilakukan untuk mngetahui mekanisme forklift dapat berjalan dengan baik dan pembacaan sensor jarak HC-SR04 dapat berfungsi dengan baik sehingga proses naik turun dari mekanisme forklift dapat berjalandengan baik dan forklift. Motor stepper yang digunakan ialah motor stepper Nema17 seri 17HS2408 jenis bipolar denganstep angle sebesar 1.8. Step angle ini digunakan untuk mengetahui berapa step yang diperlukan untuk satu putaran. Formula untuk menghitungnya ditunjukkan pada persamaan (1). SPR merupakan singkatan dari Step per Revolution dan angka 360 itu didapatkan dari total sudut satu lingkaran.

$S P R=\frac{360}{\text { step angle }}$

Sensor HC - SR04 merupakan sensor jarak yang berbasis ultrasonik. Sensor ini digunakan pada mekanisme forklift ini untuk mengukur kepresisian ketinggian saat proses lifting dan untuk mengukur jarak AGV dengan palet. Penghitungan waktu pada sensor HC - SR04 menggunakan persamaan (2). Yang dimana sensor melakukan pembacaan selisih waktu yang ditempuh saat memancarkan dan menaerima hasil pantulan frekuensi yang dipancarkan. Hasil pembacaan sensor HC - SR04 dapat dilihat pada tabel 1 .

$S=V \times T$

Tabel 1 menunjukkan hasil pembacaan pada $\mathrm{HC}$ SR04 yang dimana mulai menunjukkan pergesaran atau selisih jarak dari sebenarnya pada jarak $25 \mathrm{~cm}$ ke atas. Namun, Pergeseran yang terjadi hanya beberapa angka dibelakang koma sehingga bisa ditoleransi. Sensor HC SR04 ini digunakan untuk mengukur ketinggian forklift dan mendeteksi jarak AGV terhadap pallet sehingga saat proses pengambilan dan pengangkatan pallet tidak terjadi tubrukan. Kenaikan ketinggian dari forklift saat mengangkat juga disesuaikan dengan jalur yang ada dan sensor HC - SR04 inilah yang mnegontrol ketinggian saat proses pengangkatan agar tidak sampai pucuk ataupun keluar jalur.

TABEL I

PENGUJIAN PEMBACAAN SENSOR HC - SR04

\begin{tabular}{|c|c|c|}
\hline $\begin{array}{c}\text { Jarak } \\
(\mathbf{c m})\end{array}$ & $\begin{array}{c}\text { Pembacaan Sensor } \\
\text { HC }- \text { SR04 }(\mathbf{c m})\end{array}$ & $\begin{array}{c}\text { Error } \\
(\boldsymbol{\%})\end{array}$ \\
\hline 5 & 5 & 0 \\
\hline 10 & 10 & 0 \\
\hline 15 & 15 & 0 \\
\hline 20 & 20,02 & 0,1 \\
\hline 25 & 25,03 & 0,3 \\
\hline
\end{tabular}

Hasil dari pengujian setelah penggabungan antara motor stepper dengan sensor HC - SR04 ditunjukkan pada tabel 1 berikut. Data pada tabel 2 tersebut menunjukkan bahwa setiap satu putaran baik naik atau turun akan selisih $1 \mathrm{~cm}$ dari posisi semula, demikian pula untuk putaranputaran selanjutnya.

TABEL II

PENGUJIAN KENAIKAN KETINGGIAN SETIAP PUTARAN

\begin{tabular}{|c|c|}
\hline SPR & Kenaikkan per SPR \\
\hline 200 & $1 \mathrm{~cm}$ \\
\hline 400 & $2 \mathrm{~cm}$ \\
\hline 500 & $2,5 \mathrm{~cm}$ \\
\hline 600 & $3 \mathrm{~cm}$ \\
\hline 800 & $4 \mathrm{~cm}$ \\
\hline 1000 & $5,3 \mathrm{~cm}$ \\
\hline
\end{tabular}

Implementasi dari mekanisnme smart forklift dibagi menjadi tiga buah batas yakni batas netral, batas bawah, dan batas atas. Setiap setelah melakukan proses pengangkatan maupun pengambilan forklift akan kembali ke posisi batas netral yakni dengan ketinggian $13 \mathrm{~cm}$. Sedangkan untuk batas atas dan bawah masing - masing 8 $\mathrm{cm}$ dan $17 \mathrm{~cm}$. Untuk mengeahui berapa jumlah putaran yang dibutuhkan dapat menggunakan persamaan (3) dari data yang ditunjukkan tabel 2.

\section{KeSIMPULAN}

Berdasarkan pengujian implementasi dari perancangan yang ada dapat disimpulkan bahwa mekanisme smart forklift ini dapat berjalan dengan baik dan tingkat kepresisiannya sendiri sangat bagus karena antara pemmbacaan sensor dengan alat ukur digital memiliki error mendekati 0\%. Proses lifting nya dapat menyesuaikan jarak untuk pengambilan palet di bagian atas maupun pada bagian bawah. Step per revolution ( SPR ) dapat diatur sesuai dengan kebutuhan dan untuk kecepatan putaran sendiri dapat diatur dari SPR tersebut dan fungsi waktunya.

\section{DAFTAR PUSTAKA}

[1] D. S. Rosyadi, "Revolusi industri 4.0: Peluang dan Tantangan Bagi Alumni Universitas Terbuka," ResearchGate, no. 2, pp. 1-10, 2018

[2] S. K. Das and M. K. Pasan, "Design and Methodology of Automated Guided Vehicle-A Review," ResearchGate, no. April, 2016.

[3] L. Schulze, S. Behling, and S. Buhrs, "Automated Guided Vehicle Systems: a Driver for Increased Business Performance," ResearchGate, vol. II, pp. 19-21, 2008.

[4] T. Ferreira and I. A. Gorlach, "Development of an automated guided vehicle controller using a model-based systems engineering approach," South African J. Ind. Eng., vol. 27, no. 2, pp. 206-217, 2016, doi: 10.7166/27-2-1327.

[5] Z. Z. Moe San, A. Thike, and D. Z. Min Oo, "Electronic Forklift by Remote Control,” Int. J. Sci. Eng. Appl., vol. 8, no. 6, pp. 162 166, 2019, doi: 10.7753/ijsea0806.1003.

[6] A. Marianto and M. Muchlas, "Rancang Bangun Robot Forklift dengan Kendali Smartphone Android Berbasis Arduino Mega 
2560," J. Ilm. Tek. Elektro Komput. dan Inform., vol. 3, no. 2, p. 65, 2017, doi: 10.26555/jiteki.v3i2.7483.

[7] T. N. Trong, "The control structure for dc motor based on the flatness control," Int. J. Power Electron. Drive Syst., vol. 8, no. 4, pp. 1814-1821, 2017, doi: 10.11591/ijpeds.v8i4.pp1814-1821.

[8] A. A. Hassan, N. K. Al-Shamaa, and K. K. Abdalla, "Comparative Study for DC Motor Speed Control Using PID Controller," Int. J. Eng. Technol., vol. 9, no. 6, pp. 4181-4192, 2017, doi: 10.21817/ijet/2017/v9i6/170906069.

[9] D. Q. Huy, J. Leuchter, J. Buzek, V. Stekly, and L. T. Bang, "Design and implementation control of interfering mobile device with stepper motor and microcontroller ATmega 16," ICMT 2017 - 6th Int. Conf. Mil. Technol., pp. 666-670, 2017, doi: 10.1109/MILTECHS.2017.7988841.

[10] O. Mahmood Altaee, A. Ibraheem Alnaib, and N. Abed AlBary Aljawady, "Design and Realization of a Stepper Motor Driver with PLC," Al-Kitab J. Pure Sci., vol. 2, no. 1, 2018, doi: 10.32441/kjps.v2i1.137.

[11] S. O. Ooko, "A Comparison of Arduino , Raspberry Pi and ESP8266 Boards," no. December, pp. 3-5, 2019.

[12] Raspberry, Raspberry Pi 4 Model B, no. June. 2019. 